\title{
O ESTADO DE ANNIMO DOS PROFESSORES NAS AULAS DE ATIVIDADE FISICA COM IDOSOS EM UM PROGRAMA DE EXTENSÃO
}

\author{
Priscilla Cardoso da Silva ${ }^{1}$ \\ Isadora Loch Sbeghen² \\ Pâmela Andrieli da Silva Tristão ${ }^{3}$ \\ Amanda Suely Rodriguez de Vargas ${ }^{4}$ \\ Eliane Jost Blessmann ${ }^{5}$
}

resumo

O trabalho com grupos de idosos exige qualificação e entendimento sobre aspectos físicos, sociais e individuais do envelhecimento. Atrelado a isto, o estado de ânimo de professores instiga por ser uma condição importante a qual pode influenciar comportamentos

1 Graduada em Bacharelado em Fisioterapia e Educação Física. Graduada em Licenciatura em Educação Física. Mestranda em Ciências do Movimento Humano na Universidade Federal do Rio Grande do Sul (UFRGS). E-mail: priscilla.cardosos@gmail.com.

2 Graduada em Licenciatura em Educação Física. Mestranda em Ciências do Movimento Humano na Universidade Federal do Rio Grande do Sul (UFRGS). E-mail: ilssbeghen@gmail.com.

3 Graduada em Bacharelado em Educação Física. Graduanda do Curso de Licenciatura em Educação Física na Universidade Federal do Rio Grande do Sul (UFRGS). E-mail: pamela.treinamento@gmail.com. 4 Graduada em Licenciatura em Educação Física. Mestre em Saúde Coletiva pela Universidade Federal do Rio Grande do Sul (UFRGS). E-mail: amanda.rvargas2@gmail.com.

5 Graduada em Assistência Social. Doutoranda em Memória Social e Bens Culturais no Centro Universitário LA SALLE (UNILASALLE). E-mail: eliane.blessmann@gmail.com. 
afetivos e cognitivos em meio ao trabalho. O objetivo deste estudo é verificar a interferência da aula de atividade física no estado de ânimo dos professores de um programa de extensão ao ministrar aulas para alunos idosos. Este estudo é de natureza mista, com amostra não aleatória, por conveniência e acessibilidade. A amostra foi composta por oito professores acadêmicos de um programa de extensão universitária. Foram realizadas duas intervenções para os professores, antes e ao término das aulas, sendo os instrumentos: a Lista de Estados de Ânimo - Reduzida e llustrada (LEA-RI) e um questionário com questões abertas. Foi realizada análise estatística com prova binomial e Qui-quadrado da LEA-RI, pelo software estatístico SPSS (18.0), frequência e a análise de conteúdo para os questionários. Dos resultados obtidos pela análise estatística, verificou-se que o estado de ânimo dos professores que apresentou alteração significativa foi o "cheio de energia". Ao associar aos questionários pode-se depreender que, alguns fatores contribuem para o estado de ânimo referido, tendo por base os elementos categorizados em participação dos alunos, a dinâmica/metodologia da aula e a postura do professor. Pode-se concluir que determinados fatores interferem positivamente no estado de ânimo do professor durante as suas aulas e na relação com os alunos idosos.

palavras-chave

Estado de Ânimo. Professor. Extensão Universitária. Idosos.

\section{Introdução}

As universidades, através das suas ações extensionistas, têm buscado atender a comunidade, fomentando ações integrativas entre o mundo acadêmico e a população (POSSAMAI, 2017). As atividades extensionistas constituem-se em um campo estratégico na relação com a sociedade mediante a prestação de serviços, ao mesmo tempo em que contribuem na formação dos acadêmicos propiciando-lhes o conhecimento e a prática no trabalho com um segmento da população, no caso, idosos.

O Programa CELARI (Centro de Estudos de Lazer e Atividade Física para o Idoso) é um programa de extensão da Universidade Federal do Rio Grande do Sul (UFRGS), localizado na Escola de Educação Física, Fisioterapia e Dança (ESEFID). O trabalho é estruturado, segundo Blessmann (2014), em dois grandes 
eixos: um relacionado à prática de atividade física, que é organizado através de oficinas de hidroginástica, jogging aquático, natação, equilíbrio, ginástica funcional, ginástica localizada, musculação, dança e o PAIF (Promovendo autonomia e independência funcional); e o outro eixo com atividades socioeducativas, que incluem as atividades sociais, recreativas e oficinas culturais.

Consolidado em meio à Universidade, o mesmo foi sendo ampliado de modo que atualmente conta com 203 idosos, com idade média de 73 anos e perfil sociodemográfico heterogêneo. Com atividades ofertadas de segunda à sexta-feira, a equipe se organiza por turnos e oficinas, de modo que todas as demandas sejam diariamente cumpridas. As oficinas são realizadas duas vezes por semana, com aulas de 45 a 50 minutos, sendo estas ministradas por professores acadêmicos do curso de Graduação de Educação Física da UFRGS.

Para atender as demandas exigidas no programa de extensão, convém ressaltar o interesse do acadêmico, sua experiência e sua formação em gerontologia. Sendo importante considerar também suas habilidades, atitudes e crenças sobre a velhice, que serão determinantes nas relações estabelecidas entre professor e aluno. Da mesma forma o estado de ânimo é uma condição afetiva que influencia grande parte das respostas afetivas, cognitivas e comportamentais e que podem interferir no êxito das atividades propostas (DEUTSCH, 1997), com isso justifica-se a importância de seu estudo junto aos professores acadêmicos que atuam no programa. Segundo Isler, Avi e Machado (2012) o estado de ânimo também é considerado como vários estados afetivos superficiais, ou de menor intensidade, podendo ser difuso ou global, por isso influenciam diversas respostas positivas ou negativas que permitem uma ação reguladora. Ao contrário das emoções, o estado de ânimo não tem alvos e impulsos comportamentais específicos associados a ele, ou seja, os estados de ânimo são gerais, difusos e menos intensos dependendo dos acontecimentos do momento, como o ato de ensinar.

Vergara (2006) afirma que os estados de ânimo são alterados e encontrados quando se tem um intenso envolvimento emocional, vivências de emoções fortes, alterações endócrinas e fisiológicas e/ou por perturbação do sistema nervoso, condições as quais os professores estão submetidos nas aulas. E, além disso, os estados de ânimo têm influência em vários aspectos, tanto no cognitivo, na organização de informações, na memorização, bem como no aspecto afetivo, como intensificação ou atenuação da resposta emocional, de acordo com o episódio ou evento e circunstâncias encontradas no meio externo, podendo interferir na atitude do professor para a condução das aulas. Volp (1997) conclui que os estados de ânimo estão mais ligados às interações do que à personalidade, podendo sofrer influências de vários fatores, estes positivos ou negativos, 
mediante o qual o indivíduo vivencia as suas atividades. Compreende-se que os alunos sofrem alterações nos seus estados de ânimo nas aulas de atividade física devido as suas relações pessoais e ao exercício físico (SILVA, 2014) e muitos estudos investigam o estado de ânimo dos alunos no contexto da aprendizagem (NAKAMURA; DEUSTCH; KOKUBUN, 2008; LONGARAY; RIBEIRO; BEHAR, 2013; VENDRUSCULO; BERCHT, 2015) o que nos levou a pesquisar sobre o estado de ânimo do professor. Diante dessa afirmação, o objetivo deste estudo é verificar a interferência da aula de atividade física no estado de ânimo dos professores de um programa de extensão ao ministrar aulas para alunos idosos.

\section{Método}

Este estudo é caracterizado como de natureza mista, quantitativa e qualitativa, com amostra não aleatória, por conveniência e acessibilidade. Creswell e Plano Clark (2011) apud Paranhos et al. (2016), definem métodos mistos como um procedimento de coleta, análise e combinação de técnicas quantitativas e qualitativas em uma pesquisa, esse método se justifica pela interação entre eles, proporcionando melhores possibilidades analíticas.

A amostra foi composta por oito professores acadêmicos do programa de extensão CELARI, sendo quatro do 4 masculino e 4 do sexo feminino, com média de idade de 21,75 anos, vinculados ao curso de Licenciatura em Educação Física.

Foram avaliados 8 professores acadêmicos de 9 oficinas do programa, como apresentado no Quadro 1, sendo realizadas duas intervenções (antes e depois das aulas) para cada professor nas oficinas.

Quadro 1 - Lista de oficinas com seus respectivos professores.

\begin{tabular}{|l|c|c|c|c|c|c|c|c|c|}
\hline \multirow{2}{*}{ OFICINA } & \multicolumn{3}{|c|}{ Musculação } & \multicolumn{3}{c|}{ Equilíbrio } & \multirow{2}{*}{ PAIF } & $\begin{array}{c}\text { Ginástica } \\
\text { Funcional }\end{array}$ & $\begin{array}{c}\text { Ginástica } \\
\text { Localizada }\end{array}$ \\
\cline { 2 - 11 } & 1 & 2 & 3 & 1 & 2 & 3 & & & \\
\hline Professor Amarelo & & & & & & & $\times$ & & \\
\hline Professor Roxo & & & & $\times$ & $\times$ & & $\times$ & & \\
\hline Professor Azul & & $\times$ & & & & & & & \\
\hline Professor Branco & & & & & & & & $\times$ & \\
\hline Professor Verde & $\times$ & $\times$ & $\times$ & & & & & & \\
\hline Professor Cinza & $\times$ & & $\times$ & & & & & $\times$ & $\times$ \\
\hline Professor Rosa & & & & $\times$ & $\times$ & & & & \\
\hline Professor Preto & & & & & & $\times$ & & & \\
\hline
\end{tabular}

Fonte: Elaborado pelas autoras, 2018. 
Cabe colocar que o CELARI tem como característica oferecer aulas, denominadas "oficinas", aos alunos idosos, com dois professores acadêmicos em cada turma. Essa proposta se justifica pelo fato de que ao atuarem em duplas proporcionam aos professores acadêmicos uma maior segurança e troca de saberes em meio a organização e desenvolvimento das aulas. Neste estudo, a amostra é de 8 professores para 5 oficinas, justificado pela exclusão de 2 professores que não responderam à todos os instrumentos propostos para coleta de dados, de modo que os mesmos não foram contemplados nas análises de resultados. Todos os professores acadêmicos assinaram o Termo de Consentimento Livre e Esclarecido. Cabe salientar que a música foi extinta das aulas, por ser um fator de influência externo que poderia interferir positiva ou negativamente no estado de ânimo dos participantes.

Para a coleta de dados foram utilizados dois instrumentos, a Lista de Estados de Ânimo - Reduzida e Ilustrada (LEA-RI) e um questionário com questões abertas, respondidos antes de iniciar a aula e ao término da aula, respectivamente. A Lista de Estado de Ânimo - Reduzida e Ilustrada (LEA-RI), desenvolvida por Volp (1997) proporciona uma maior compreensão do estado de ânimo, classificando os estados de ânimo em adjetivos, como feliz/alegre, pesado/cansado/carregado, agradável, triste, espiritual/sonhador, leve/suave, cheio de energia, ativo/energético, agitado/nervoso, desagradável, calmo/tranquilo, inútil/apático, tímido e com medo, e para cada adjetivo há uma classificação de intensidade (muito forte, forte, pouco, muito pouco), todos os adjetivos descritos através de figuras faciais e quadros, nos quais exemplificam e ilustram o adjetivo e a intensidade do estado de ânimo. Já o questionário com questões abertas aos professores viabiliza a compreensão do tempo de experiência acadêmica e profissional, reflexões sobre a aula e relacionamento com os alunos.

Os resultados foram analisados em duas etapas, na primeira etapa foi feita a análise estatística com prova binomial e Qui-quadrado da LEA-RI, pelo software estatístico SPSS (18.0). Na segunda etapa foi realizada a análise dos questionários através da análise de conteúdos buscando verificar a associação entre o estado de ânimo e as respostas dos professores acadêmicos.

\section{Resultados e Discussão}

Nessa primeira análise da pesquisa são apresentados e discutidos os resultados obtidos dos valores brutos dos adjetivos do LEA-RI pela prova binomial do fator mudança dos professores. O procedimento de análise seguiu a estrutura descrita por Gobbi et al. (2007), que define como significativos os adjetivos que 
apresentaram mais " 0 " do que " 1 " para a não mudança. Sendo assim, todos os adjetivos que apresentaram $p<0,05$ são classificados como estáveis, ao contrário dos adjetivos que apresentaram $p>0,05$, que são definidos como modificados.

A Tabela 1 apresenta os adjetivos e os valores de significância e não significância dos 14 adjetivos da LEA-RI, dos quais 6 adjetivos (feliz/alegre; triste; espiritual/sonhador; inútil/apático; tímido e com medo) apresentaram não modificação $(p<0,05)$. Isso significa que esses adjetivos apresentaram valores para antes e depois da aula parecidos ou iguais (maior quantidade de " 0 "), não havendo grande modificação para essas sensações. Os demais adjetivos, pesado/cansado/carregado; agradável; leve/suave; cheio de energia; ativo/energético; agitado/nervoso; desagradável; e calmo apresentaram modificação, indicando que obtiveram valor "1", a proporção de mudança foi maior em comparação dos valores antes e pós-aula.

Tabela 1 - Resultados da prova binomial para o fator mudança dos professores.

\begin{tabular}{lll}
\hline Adjetivo & $\mathrm{P}<0,05$ & Conclusão \\
\hline Feliz/Alegre & 0,021 & Não modificou \\
Triste & 0,004 & Não modificou \\
Espiritual/Sonhador & 0,021 & Não modificou \\
Inútil/Apático & 0,004 & Não modificou \\
Tímido & 0,021 & Não modificou \\
Com medo & 0,001 & Não modificou \\
Pesado/Cansado/Carregado & 0,210 & Modificou \\
Agradável & 1,000 & Modificou \\
Leve/Suave & 0,804 & Modificou \\
Cheio de Energia & 0,454 & Modificou \\
Ativo/Energético & 0,454 & Modificou \\
Agitado/Nervoso & 0,454 & Modificou \\
Desagradável & 0,454 & Modificou \\
Calmo & 0,454 & Modificou \\
\hline
\end{tabular}

Fonte: Elaborada pelas autoras, 2018.

Os adjetivos denominados pesado/cansado/carregado; agradável; leve/ suave; ativo/energético; agitado/nervoso; desagradável; e calmo não apresentaram valores significativos, indicando que apesar dos adjetivos sofrerem modificações, essas não apresentaram valores suficientes para uma modificação significativa.

Para a análise do fator direção, a prova binomial foi realizada apenas com os dados que apresentaram modificação na primeira análise (fator mudança) e com 
ordem inversa, ou seja, os adjetivos que apresentavam $\mathrm{p}>0,05$ indicavam uma variação (direção) não significativa, enquanto que os adjetivos que apresentavam $\mathrm{p}<0,05$ indicaram uma variação (direção) significativa, apresentando uma direção crescente dos resultados, ou seja, os valores aumentaram no LEA-RI no pós-aula.

Tabela 2 - Resultado da prova binomial para o fator direção dos professores.

\begin{tabular}{l|l|l}
\hline Adjetivo & Direção & $p$ \\
\hline Cheio de Energia & Crescente & 0,031 \\
\hline
\end{tabular}

Fonte: Elaborada pelas autoras, 2018.

A Tabela 2 elucida as alterações das intensidades do adjetivo "cheio de energia" no estado de ânimo dos professores acadêmicos. O adjetivo apresentou um aumento da intensidade, com migração dos valores muito pouco e pouco em direção aos valores forte e muito forte, indicando um aumento do sentimento de energia após a aula. $\mathrm{Na}$ análise com o Qui-quadrado verificou-se a migração das intensidades, por exemplo, 2 professores migraram de muito pouco para pouco e 3 migraram de pouco para forte e assim sucessivamente.

Assim, a maioria dos professores apresentaram uma alteração positiva no estado de ânimo, ou seja, existiu um aumento da sensação cheio de energia. $O$ adjetivo cheio de energia envolve vários aspectos positivos, desde fisiológicos aos emocionais, incluindo fatores psicológicos e sociais, de modo que se apresenta certa complexidade no entendimento desse sentimento (CATIB et al., 2008).

Esta alteração do estado de energia pode ter sido modificada por vários fatores, através dos questionários buscamos obter informações pertinentes, como a experiência profissional dos professores acadêmicos, a qual pode influenciar tanto na condução da oficina, por ter mais ou menos experiência, e as questões referentes às suas opiniões sobre a aula e as relações pessoais, fatores que podem interferir na sua conduta e ações durante a aula. Assim, os questionários serão apresentados de forma descritiva e pelo método de análise de conteúdo (BARDIN, 2011), constituindo a segunda etapa da análise dos dados.

Uma das primeiras questões foi sobre o tempo de estudos no curso de Licenciatura em Educação Física, no qual 25\% $(n=2)$ dos professores acadêmicos relataram estar no início do curso, $50 \%(n=4)$ no meio do curso e $25 \%(n=2)$ ao final do curso. Como $75 \%$ dos professores já estão na metade do curso ou final, eles já têm em sua bagagem um pouco mais de conhecimento para embasar a sua ação. A formação do professor reúne os saberes científicos e pedagógicos que são a base sólida para a prática da ação de ensinar (ROLDÃO, 2007) e essa ação de ensinar, ou melhor, de aprender a ensinar, se torna fortificada pelas experimentações proporcionadas pelos programas de extensão. 
Essa ação se faz importante na formação dos futuros professores no qual a teoria se transforma em prática, dos professores acadêmicos pesquisados, $12,5 \%(n=1)$ possuía quatro anos de experiência como professor, $50 \%(n=4)$ dois anos de experiência, $12,5 \%(n=1)$ um ano de experiência e $25 \%(n=2)$ menos de seis meses de experiência como professor. A experiência como professor quando ainda estudante fortalece a aprendizagem e contribui para a sua capacidade de ação e adaptação perante as dificuldades, por isso, o professor tem que estar receptivo a novas experiências que ocorrem no decorrer das aulas e deve canalizar os fatos para lidar adequadamente com as suas emoções.

Essa habilidade de adaptação se reforça ao trabalhar com um público diferenciado, como idosos, pois essas diferenças intergeracionais oferece ao professor uma "carga emocional positiva presente nessa relação que é considerada fundamental para manterem-se comprometidos e realizados" (LÜDKE; BOING, 2012, p. 432) profissionalmente ao trabalharem com esse público.

As experimentações do trabalho com o público idoso na Universidade são facilitadas pelos programas de extensão, mas principalmente pela identificação e interesse do acadêmico, assim 12,5\% (n=1) dos professores acadêmicos participava há quatro anos do programa, 37,5\% $(n=3)$ estava há dois anos e $50 \%(n=4)$ estava há menos de seis meses no CELARI. Sobre o tempo que leciona na oficina $25 \%(n=2)$ há um ano, $12,5 \%(n=1)$ há sete meses e os demais professores por menos de cinco meses. De forma geral, há uma boa adesão e permanência dos professores acadêmicos no programa de extensão CELARI com uma renovação no semestre de 50\%. O nível de experiência na docência com o público idoso foi relevante no estudo de Alves (1997), no qual os alunos idosos justificaram sua evasão as aulas por motivos de inexperiência dos professores, que tornavam as aulas monótonas ou extensas, com metodologia para os alunos tradicionais, não sendo específica para os alunos idosos, dispensando seus interesses e características.

Para ensinar o público idoso, o professor acadêmico de Educação Física necessita possuir conhecimento, reflexão e preparo para os diversos aspectos mutáveis do processo de envelhecimento, nas mudanças motivacionais e fisiológicas, nos aspectos físicos, nas diferentes crenças e hábitos de vida diários, e na idade cronológica e biológica de cada aluno (FARIA JUNIOR, 1999; VAGETTI; ANDRADE, 2006). Esses conhecimentos e habilidades não podem ser adquiridos apenas em aulas teóricas, e sim, na sua prática, "por isso é que, na formação permanente dos professores, o momento fundamental é da reflexão crítica sobre a prática. É pensando criticamente a prática de hoje ou de ontem que se pode melhorar a próxima prática" (FREIRE, 2002, p. 39). Enfatizando que a formação docente deve ser embasada na reflexão das aulas, na prática, 
como professor e na valorização das emoções, essas que através da segurança e motivação podem promover ao professor um estado de ânimo mais positivo.

A análise de conteúdo referente às opiniões sobre a aula e as relações pessoais, tiveram origem nas perguntas: "Você gostou da aula?", "Ao refletir sobre os alunos, o que pensa que os alunos acharam das aulas? (explique os motivos)" e "Como você se relaciona com os alunos?".

Das respostas emergiram três categorias, a primeira seria a participação dos alunos nas aulas, a segunda a dinâmica/metodologia da aula e a terceira a postura do professor.

Participação dos alunos:

"Todos os alunos foram bem ativos e participativos" (professor verde).

"Eles se envolveram nos exercícios propostos", "Acredito que gostaram pelo esforço percebido em aula e sua dedicação" (professor branco).

"Todos eles sempre aplaudem o fim da aula mostrando gratificação conosco", "Eles adoram, não reclamam e elogiam" (professor verde).

"A maioria saiu sorridente e bem descontraída" e "Todos pareciam alegres, sorridentes e alguns brincalhões" (professor cinza).

Percebe-se que as relações interpessoais são estabelecidas nas aulas de atividade física, devido algumas características peculiares que fundamentam uma dimensão mais humanista nas aulas, tanto o ambiente quanto o movimento/exercício propicia uma relação de proximidade com o aluno. As relações estabelecidas entre professor-aluno são uma forma de interação que dá sentido ao processo educativo (SILVA; NAVARRO, 2012) e o afeto, como principal componente nas relações humanas exerce papel fundamental para o êxito das aulas. Os alunos não se constrangiam em dar retorno em cada oficina. Para estes professores o retorno foi positivo, conforme demonstrado através da participação.

As emoções dos alunos foram observadas e percebidas de inúmeras formas por professores diferentes em suas observações, como na postura corporal, nos movimentos, no tom de voz, e até pela própria expressão facial (DAMASIO, 2000 apud SANTOS, 2007). Fatores esses que podem influenciar o estado de ânimo dos professores, se sentindo recompensados e cheios de energia.

Dinâmica da aula:

"Sim, foi um pouco mais tranquila que o normal, por que estava sem música" (professor cinza).

"Todos sentiram a falta da música e notei que ficaram cansados no final" (professor amarelo). 
A música não foi utilizada nas aulas propositalmente por ser considerado um evento externo que pode interferir positivamente nos estados de ânimo, devido a sua ação motivadora (SEKEFF, 2002; MORI; DEUTSCH, 2005), em outro estudo sobre a influência da música preferida e não preferida na atividade física vigorosa, verificaram que a musica não influencia no exercício, mas é capaz de melhorar os estados de ânimo positivos (NAKAMURA; DEUSTCH; KOKUBUN, 2008), devido ao fato de que a música causa motivação, distração e proporciona uma atitude mental positiva (MIRANDA; GODELI, 2003).

Visto que, no estudo de Mori e Deutsch (2005), nas aulas sem a presença da música as alunas sentiram-se mais pesadas e menos leves, justificando a percepção do professor sobre o fato dos alunos estarem cansados no final da aula, fato que corroborou com a percepção dos professores quanto à influência ambiental.

\section{"A aula alcançou o objetivo principal de trabalhar o equilíbrio", "A aula foi dinâmica e tivemos um bom retorno da turma" (professor roxo). \\ "Eles se envolveram nos exercícios propostos... Gostaram da aula, pois todos conseguiram realizar o seu treino sem nenhuma dor, cansaço ou outro tipo de problema" (professor branco). \\ "Considero as limitações deles na hora de planejar as aulas" (professor roxo).}

O professor não deve subestimar o aluno idoso, não deve tratá-lo com cuidados excessivos, deve sim, estimular seu desenvolvimento, independência e autonomia, estimulando as suas capacidades, demonstrando segurança na condução dos exercícios. De forma, ao organizar as atividades considerar os interesses, expectativas e necessidades dos seus alunos idosos (OKUMA, 1998; OKUMA apud FREITAS, 2002).

O professor também deve empenhar-se em promover a aprendizagem de seu aluno, através de um planejamento das aulas global que contemple as necessidades, limitações e capacidades de seus alunos. Nesse sentido, o aluno, enquanto sujeito, pode ser ativo e interativo na construção das suas atividades e conhecimento (TREVISOL; SOUZA, 2015). Essa transmissão de informação, de conteúdo, de troca de aprendizagem e afetividade contribui para que o professor consiga mediar, dialogar, problematizar e indagar os conteúdos a serem aprendidos, além de aumentar a sua energia e disposição ao ministrar as aulas (CRUZ; MAGALHÃES, 2017). E proporcionar ao aluno melhora dos componentes de aptidão física, independência, autonomia, aumento da autoestima, integração e socialização, fatores que podem fortalecer a sua "visão" como professor e aumentar sua disposição e energia. 
Postura do professor:

"Converso com todos, brincamos e nos divertimos bastante, eles me respeitam assim com eu respeito eles. Temos um ótimo convívio" (professor cinza).

"Temos uma relação maior que professor-aluno, mas sim de amizade" (professor branco).

"Nunca houve nenhum tipo de desentendimento, sempre conversamos antes das aulas e há um ótimo relacionamento entre eles" (professor amarelo).

"Me relaciono de forma próxima e sempre tentando deixar o aluno a vontade e seguro" (professor azul).

"Me relaciono muito bem, converso com todos, procuro conhecer cada um e suas limitações, fazendo o possível para ajudar" (professor rosa).

"Tenho uma relação bem próxima com eles. Busco ser atenciosa com todos e motivá-los na realização das aulas. Ajudo a superar suas limitações e incentivo a autonomia em todas as aulas" (professor preto).

Para Santos (1997), a postura do professor define as ações dos alunos. “O professor através de sua ação pode formar simpatias ou antipatias em relação a determinados conteúdos e isso depende, em grande medida, da sua própria relação com o conteúdo que ele ensina" (SANTOS, 1997, p. 254).

Um bom professor deve ter como características principais o conhecimento de sua matéria, a habilidade para organizar as aulas e a manutenção de relações positivas (CUNHA, 1992). Acrescentando, Lopes, Farias e Pires (2012) afirma que para trabalhar com o público idoso e atividade física são importantes algumas habilidades ao professor, como: saber escutar, ser paciente, carismático, comunicativo, responsável, socioafetivo, gostar e se interessar pela terceira idade; buscando em suas aulas um ambiente agradável, seguro, estimulante, sociável e afetuoso.

Através desse ambiente propício para o aprendizado ocorrem às relações entre professores e alunos. A importância dessa relação no processo de ensino aprendizagem compreende-se por um dos principais componentes das relações humanas, o profundo afeto (SILVA; NAVARRO, 2012). Cachione (2003) afirma que, em programas, os idosos tendem a serem mais participativos, dinâmicos e amistosos, e os professores destes grupos tendem a receber afeição, carinho e gratidão.

Esses fatores podem favorecer um aumento do estado de ânimo "cheio de energia", devido ao professor perceber a sensação de bem-estar pessoal e o sentimento de ter realizado um bom trabalho. 
Neste estudo consideramos os estados de ânimo originados a partir de estados emocionais para dizer como o professor acadêmico se sente após as aulas de atividade física ministrada a alunos idosos.

Dos resultados obtidos pela análise estatística, verificou-se que o estado de ânimo dos professores sofreram alterações, o adjetivo cheio de energia sofreu alteração significativa positivamente, nos quais os professores acadêmicos ao terminarem as aulas se sentem com mais energia. Associando aos questionários podemos depreender que alguns fatores contribuem para este estado de ânimo, tendo por base os elementos categorizados em participação do aluno nas aulas, a dinâmica/metodologia da aula e a postura do professor.

O estado de ânimo "cheio de energia" pode se relacionar com aspectos afetivos, como estar animado, disposto, entusiasmado e satisfeito, fatores que favorecem as ações pedagógicas como professor.

Um professor acadêmico de educação física que tem interesse na área de gerontologia possui obstáculos e desafios na sua formação acadêmica e profissional, necessitando buscar uma sincronia entre teoria e prática, não se esquecendo de respeitar e perceber as alterações específicas do envelhecimento.

Os programas de extensão proporcionam aos acadêmicos vivências de extrema importância para sua prática, percebemos que quanto maior o nível de formação e experiência do professor maior será a sua confiança e segurança no momento de ministrar as suas aulas, ocasionando um aumento da sua energia e o desenvolvimento de suas habilidades e competências como professor.

O professor deve proporcionar um ambiente de aula acolhedor e agradável aos alunos idosos, favorecendo a aprendizagem e as relações interpessoais, sabe-se que a postura do professor influencia na sua prática e na sua relação com os alunos, um professor mais afetuoso, ouvinte, acessível, "amigo", respeitoso e prestativo. Segundo o relato dos professores, a participação dos alunos e as relações são de fundamental importância, sendo assim o estado de ânimo positivo, cheio de energia é fortalecido pela amizade e pelo afeto ocasionando um ambiente propício às relações sociais, visto que a socialização é um aspecto essencial em grupos de idosos.

Contudo, ressaltamos a importância dos programas de extensão universitária voltados para o público idoso, por proporcionar aos professores acadêmicos vivências e experiências capazes de embasar seus saberes nas adversidades encontradas na sua vida profissional. 
THE MOOD STATE OF THE TEACHERS IN THE CLASS OF PHYSICAL ACTIVITY WITH ELDERLY IN A PROGRAM OF EXTENSION

\section{abstract}

Working with groups of older people requires qualification and understanding of physical, social and individual aspects of aging. Linked to this, the teachers' mood state instigates as an important condition that can influence affective and cognitive behavior in work. The objective of this study is to verify the interference of the physical activity class in the mood state of the teachers of an extension program when teaching classes for elderly students. This study is of mixed nature, with non-random sample, for convenience and accessibility. The sample consisted of eight academic teachers from a university extension program. Two interventions were carried out for teachers, before and after classes, with the instruments: the Reduced and Illustrated Listing of Mood State and a questionnaire with open questions. Statistical analysis with binomial and Chi-square tests, statistical software SPSS (18.0), frequency and content analysis were performed. From the results obtained by the statistical analysis it was verified that the mood state of the teachers which presented significant change was the "full of energy". Associating with the questionnaires, it can be deduced that some factors contribute to the mood state, based on the elements categorized in student participation, the dynamics/ methodology of the class and the teacher's posture. It can be concluded that certain factors interfere positively in the mood state of the teacher during their class and in the relationship with the elderly students.

keywords

Mood State. Teacher. University Extension. Elderly.

referências

ALVES, Gilda. Universidade da Terceira Idade como alternativa de resgate da cidadania idosa: análise do caso da Unimep. 1997. Dissertação (Mestrado em Educação) - Universidade Metodista de Piracicaba, Piracicaba, 1997.

BARDIN, Laurence. Análise de Conteúdo. São Paulo: Edições 70, 2011.

BLESSMANN, Eliane (coord.). Vidas em movimento: nosso lugar no mundo. Porto Alegre: Yara Lima, 2014. 
CACHIONE, Meire. Quem educa os idosos? Um estudo sobre professores de universidades da terceira idade. Campinas: Alínea, 2003.

CATIB, Norma et al. Estados emocionais de idosos nas danças circulares. Revista Motriz: Revista de Educação Física, Rio Claro, v. 14, n. 1, p. 41-52, jan./mar. 2008.

CRUZ, Giseli; MAGALHÃES, Priscila. O ensino de didática e a atuação do professor formador na visão de licenciados de educação artística. Educação e Pesquisa, São Paulo, v. 43, n. 2, p. 483-498, abr./jun. 2017.

CUNHA, Maria Isabel da. O bom professor e sua prática. 2. ed. São Paulo: Papirus, 1992.

DEUTSCH, Silvia. Música e Dança de Salão: interferências da audição e da dança nos estados de ânimo. 1997. 165 f. Tese (Doutorado em Psicologia Experimental) - Instituto de Psicologia, Universidade de São Paulo, São Paulo, 1997.

FARIA JUNIOR, Alfredo (org.). Ginástica, dança e desporto para a terceira idade. Brasilia: SESI/INDESP, 1999

FREIRE, Paulo. Pedagogia da autonomia: saberes necessários à prática educativa. Rio de Janeiro: Paz e Terra, 2002.

FREITAS, Elizabete et al. (org.). Tratado de geriatria e gerontologia. Rio de Janeiro: Guanabara Koogan, 2002. p. 1092-1100.

GOBBI, Sebastião et al. Efeitos da dança e do treinamento com pesos nos estados de ânimo de idosos. Journal of Physical Education, v. 18, n. 2, 2007.

ISLER, Gustavo; AVI, Gisele; MACHADO, Afonso. O envolvimento de idosas em uma competição de dança: um olhar sobre seus estados de ânimo. Coleção Pesquisa em Educação Física, Várzea Paulista, v. 11, n. 5, 2012.

LONGARAY, Ariane; RIBEIRO, Ana; BEHAR, Patrícia. Estratégias pedagógicas para a educação a distância: um olhar a partir dos estados de ânimo do aluno. Nuevas Ideas en Informática Educativa TISE, p. 606-609, 2013.

LOPES, Marize; FARIAS, Sidney; PIRES, Patrícia. Conhecimento e habilidades necessárias ao profissional de educação física para atuar com idosos. Estudos Interdisciplinares sobre o Envelhecimento, Porto Alegre, v. 17, n. 1, p. 91-110, 2012.

LÜDKE, Menga; BOING, Luiz. Do trabalho à formação de professores. Cadernos de Pesquisa, São Paulo, v. 42, n. 146, p. 428-451, maio/ago. 2012.

MIRANDA, Maria Luiza; GODELI, Maria Regina. Música, atividade física e bem-estar psicológico em idosos. Revista Brasileira de Ciência e Movimento, Brasília, DF, v. 11 , n. 4, p. 87-94, out./dez., 2003

MORI, Patrícia; DEUTSCH, Silvia. Alterando estados de ânimo nas aulas de Ginástica rítmica com e sem a utilização de música. Revista Motriz, Rio Claro, v. 11, n. 3, p. 161-166, set./dez. 2005

NAKAMURA, Priscila; DEUSTCH, Silvia; KOKUBUN, Eduardo. Influência da música preferida e não preferida no estado de ânimo e no desempenho de exercícios realizados na intensidade vigorosa. Revista Brasileira de Educação Física e Esporte, São Paulo, v. 22, n. 4, out./dez. 2008.

OKUMA, Silene. O idoso e a atividade física: fundamentos e pesquisa. Campinas: Papiros, 1998.

PARANHOS, Ranulfo et al. Uma introdução aos métodos mistos em Ciência Política. Sociologias, Porto Alegre, v. 18, n. 42, p. 384-411, maio/ago. 2016.

POSSAMAI, Vanessa. Percepção dos idosos participantes de um programa de extensão sobre os pressupostos da política de envelhecimento ativo. 2017. Dissertação (Mestrado em Saúde Coletiva) - Faculdade de Enfermagem, Universidade Federal do Rio Grande do Sul, Porto Alegre, 2017. 
ROLDÃO, Maria. Função docente: natureza e construção do conhecimento profissional. Revista Brasileira de Educação, Rio de Janeiro, v. 12, n. 34, p. 94-181, 2007.

SANTOS, Flávia. Afeto, emoção e motivação: uma nova agenda para a pesquisa em ensino de ciências. In: Encontro Nacional de Pesquisa em Ensino de Ciências, 1. 1997, Águas de Lindóia. Anais [...]. Águas de Lindóia: IF/UFRGS, 1997. p. 249-255.

SANTOS, Flávia. As emoções nas interações e a aprendizagem significativa. Revista Ensaio, Belo Horizonte, v. 9, n. 2, jul/dez., 2007.

SEKEFF, Maria. Da música: seus usos e recursos. São Paulo: Editora UNESP, 2002.

SILVA, Ormenzina; NAVARRO, Elaine. A relação professor-aluno no processo ensino-aprendizagem. Revista eletrônica interdisciplinar da univar, v. 2, n. 8, 2012.

SILVA, Priscilla. Estado de ânimo e relação professor-aluno: uma análise de intervenções didático-pedagógicas com idosos. 2014. Trabalho de Conclusão de Curso (Licenciatura em Educação Física) - Universidade Federal do Rio Grande do Sul,Porto Alegre, 2014

TREVISOL, Maria; SOUZA, Elizangela. A relação entre professor e aluno e a importância do afeto no processo de ensino-aprendizagem. Unoesc \& Ciência - ACHS, Joaçaba, v. 6, n. 1, p. 35-42, jan./jun. 2015.

VAGETTI, Gislaine; ANDRADE, Oséias. Fatores influentes sobre o processo ensino-aprendizagem na educação física para idosos. Acta Scientiarum, Maringá, v. 28, n. 1, p. 77-86, 2006.

VENDRUSCULO, Maria, BERCHT, Magda. Prática pedagógica de docentes de ciências contábeis da região sul e sudeste do Brasil: um estudo da percepção da afetividade. ConTexto, Porto Alegre, v. 15, n. 29, p. 113-128, jan./abr. 2015.

VERGARA, Réne Gallardo. Naturaleza del Estado de Ánimo. Revista Chilena de Neuropsicología, Santiago, v. 1, n. 1, p. 29-40, 2006.

VOLP, Catia. Músicas, estados de ânimo e qualidade do movimento. Relatório Trienal apresentado à Comissão Permanente de Regime de Trabalho da UNESP. Rio Claro: UNESP, 1997.

Data de Submissão: 17/09/2018

Data de Aprovação: 10/10/2018 
